\title{
التعليل الصوتي الماهر الاعلال بين النحويين المتقدمين والمتأخرين
}

دـ كريم مزعل محمد جامعة واسط / كلية الآداب

خلاصة البحث :

الإعلال من المصطلحات الثـائعة في الدرس الصرفي ، وهو قريب من در اسـة الأصسوات اللغويـة و اللهجات العربية.

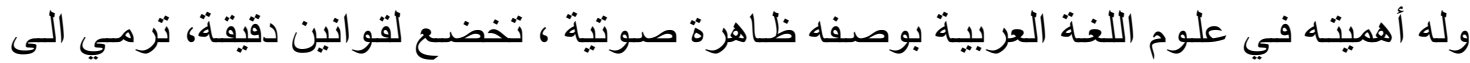

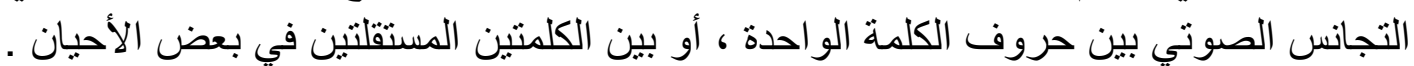

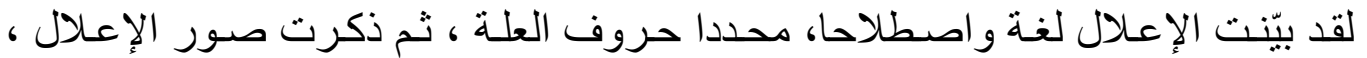

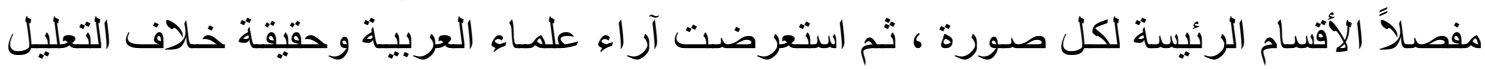

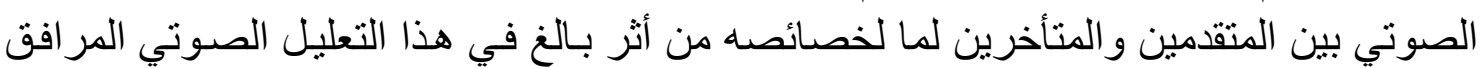

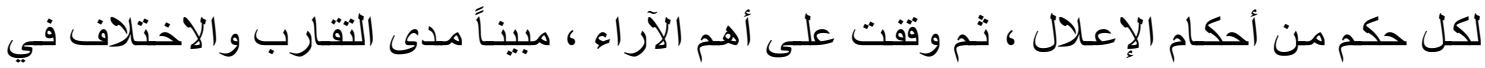
وجهات النظر الصرفية للتعليل الصوتي..

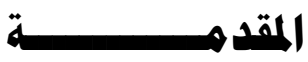

الحمد لله رب العالمين الذي بـه نستعين ، و الصـلاة و السـلام على سيد المرسـلين الرسول محمد (صلّى الله عليه وسلّم) و على آله وصحبه إلى يوم الدين ، أما بعد .....

فالبحث هو در اسة لفرع مهم في الدراسة الصرفية ، و علوم اللغة العربية عامة ، وهو ((الإعلال)) الذي يُعد من المصطلحات الثائعة في الدرس الصرفي ، ورله وله علاقة وثيقة بدر اسة اللهجات العربية

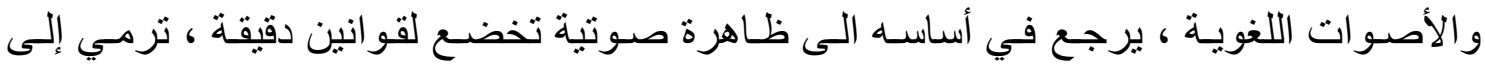
التجانس الصوتي بين حروف الكلمة الواحدة أو طلباً للخفة .

و ون خلال بحثنا هذا نحاول جاهدين السير على خطى علمـاء الصـرف المتقدمين من خـلال

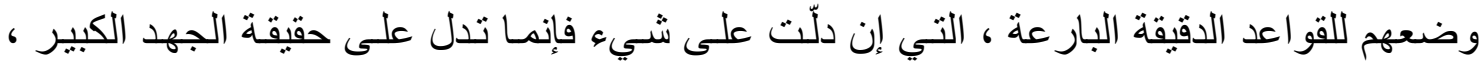

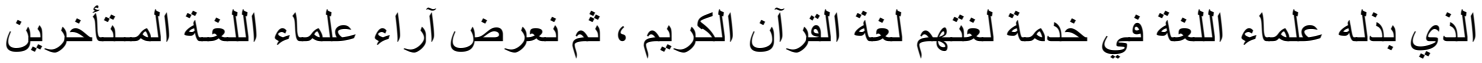

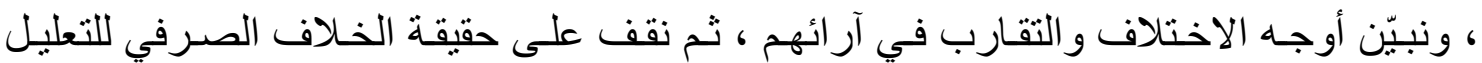

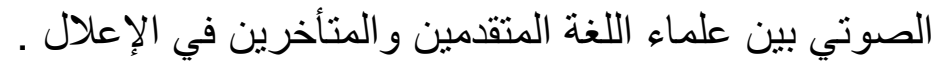

\section{الإعلال في اللغة والاصطلاح الإعلال لغة:}


من : علَّ يعلّه و اعتلَّ ، مَرِض ، و العلة : المرض. عَلَّ الرجل بَعلُْ المريض. وقد اعتلَّ العليل علة صعبة .

العلة : الحدث الذي يشغل صاحبه عن حاجته ، كأنَّ تلاك العلة صارت شغلاً ثانيـاً منعـه عن شـله (') الأولة : (1)

$$
\text { ؤهو في الأصل مصدر للفعل المزيد أعَلَّ. }
$$

و العلة تغيّر المعلول عما هو عليهه ، وسُميت هذه الحروف حروف علّة لكثرة تغيّر هـا (وهذه

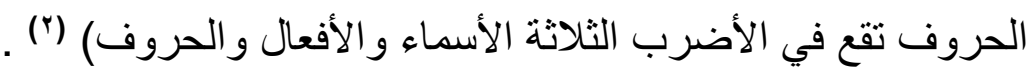

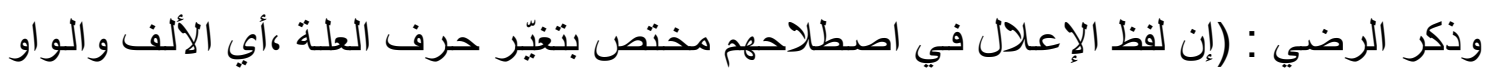

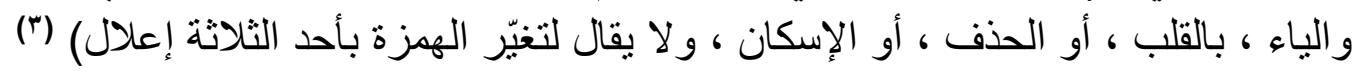

ويبدو أنّ الغاية من تغيّر حرف العلة هو للتخفيف (؛)

فالإعلال ير اد به التغيّر الذي يحدث على أحد أحرف العلة ، ويتفق جميع علمـاء اللغة المتأخرين

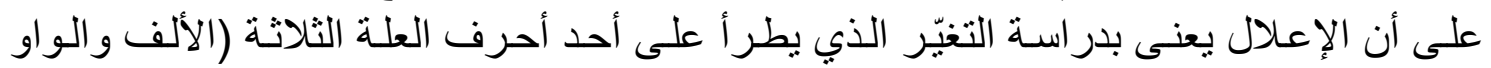

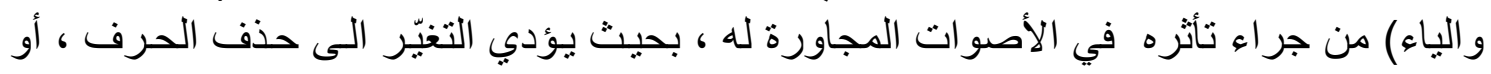

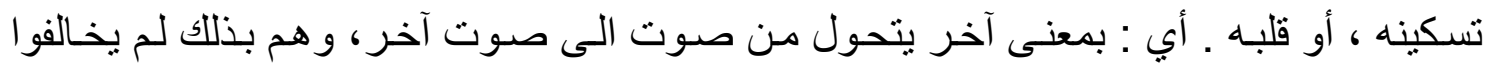

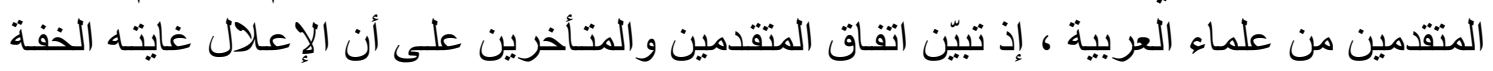

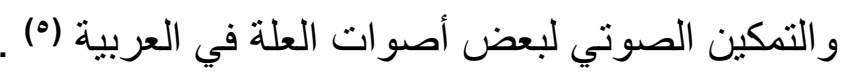

\section{حديد حروف العلة}

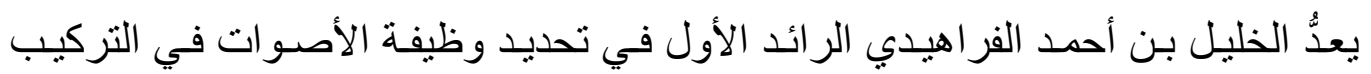

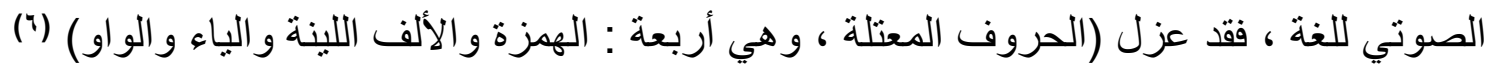

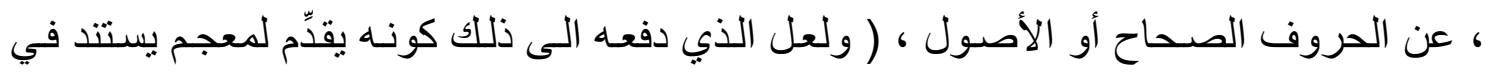

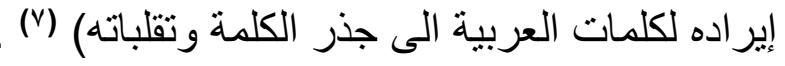

أما سيبويه فقد أبعد الهمزة عن هذه الأصوات ، فالأصوات تبدأ عنده بالهمزة ثم الألف (^) . 
ونجد ابن يعيش منأثراً فيما جاء على لسان سيبويه في حروف العلـة إذ يقول (حروف العلـة التي

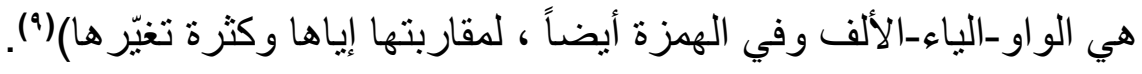

وقال الرضي : (ويعني بحروف العلة الواو والياء والألف ، و إنما سميت أحرف علّة لأنها لا تسلم

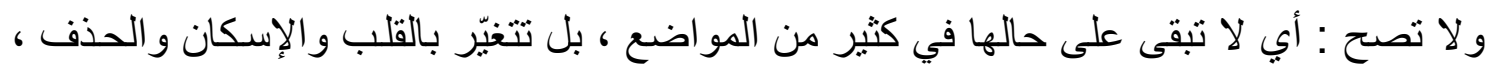

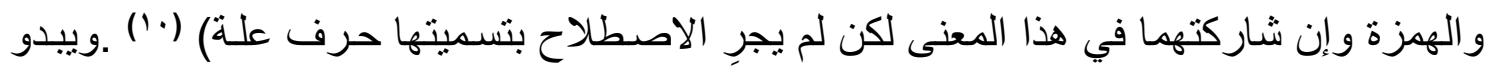

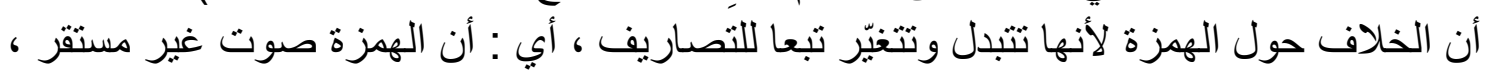

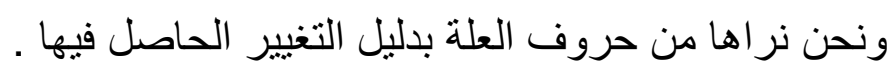

وحروف العلة و الاعتلال هي الألف و الياء و الواو ، وسُميت بذلك للينها وموتها (')'.

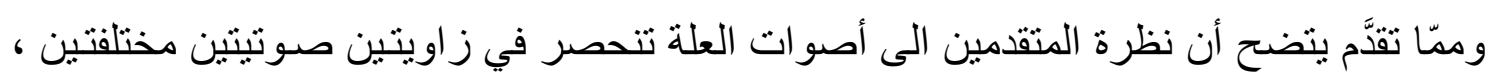

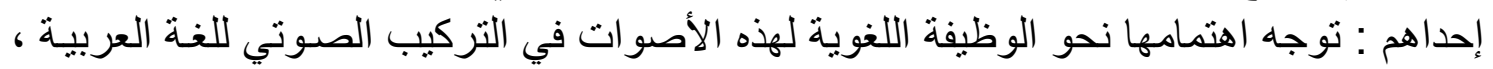

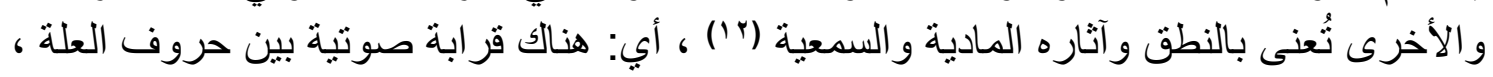

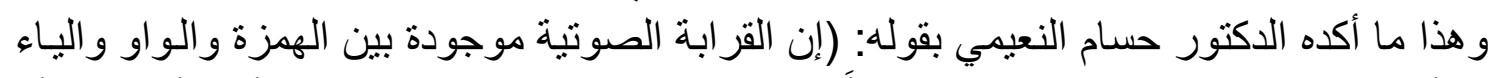

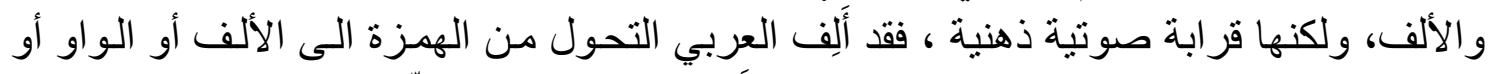

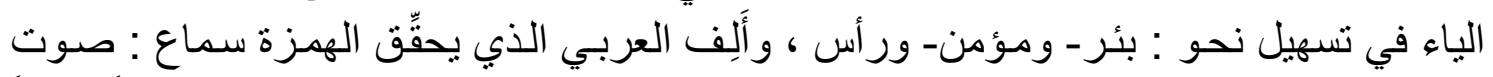

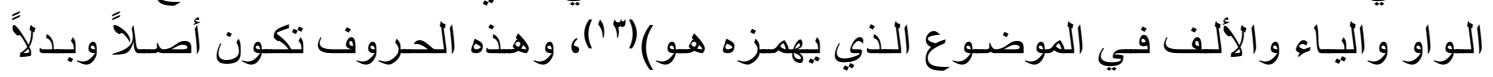

وز ائدة) (1)

صـور الإعـلال

صور الإعلال ثلاث هي : (10) اولاً : الإعلال بالقلب : وهو قلب أحد حروف العلة حرفاً آخر ، وذلك على النحو الآتي :

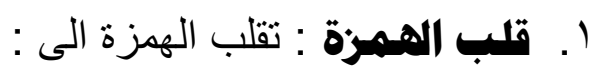

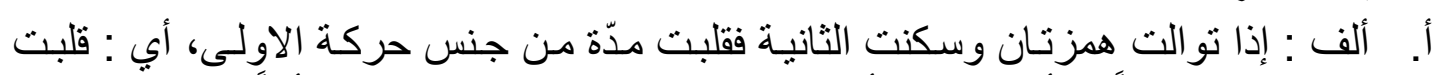

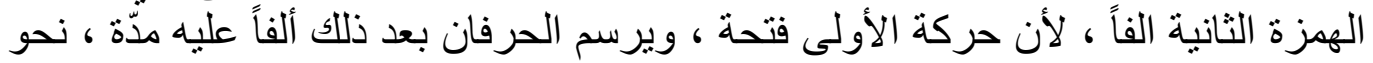

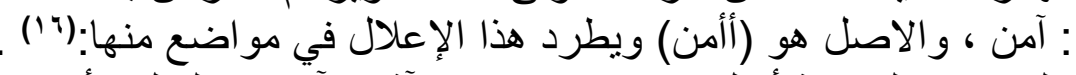

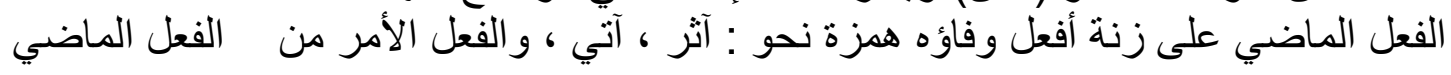

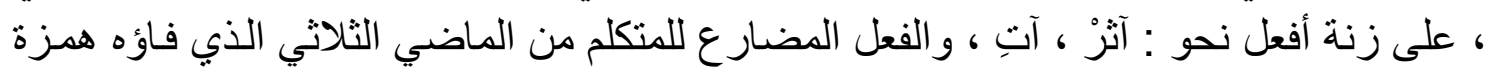

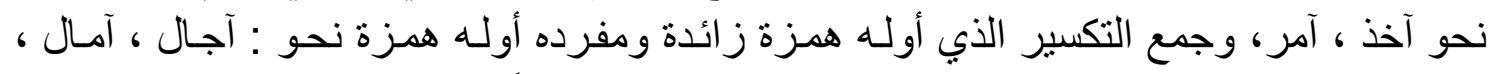

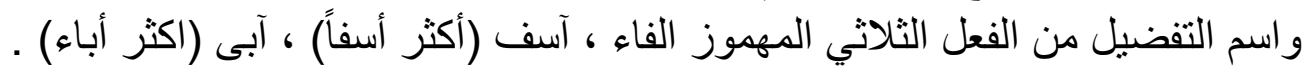


ب. و او : تقلب الهززة واواً إذا توالت همزتان وكانت الأولى متحركة بالضم و الثانية ساكنة ،

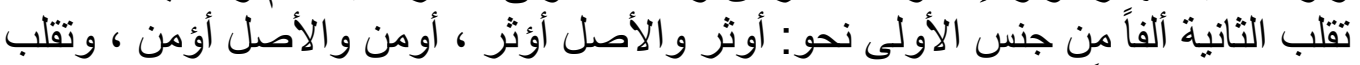

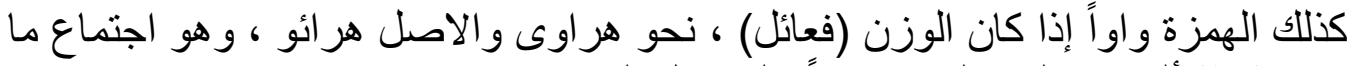

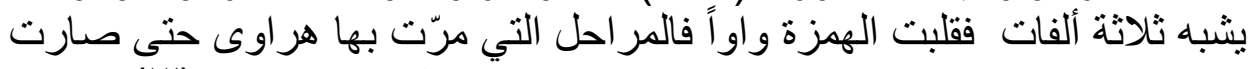

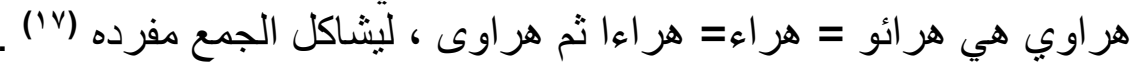

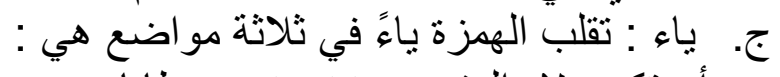

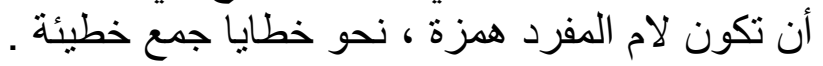

$$
\text { أو باء أصلية نحو قضايا جمع قضية . }
$$

أو واواً منقلبة عن ياء مطيه إذ أصلها مطيوه وهو الظهر من المطأ ، أو من المطو وهو

$$
\text { r. قلب الألف : تقلب الألف الى : }
$$

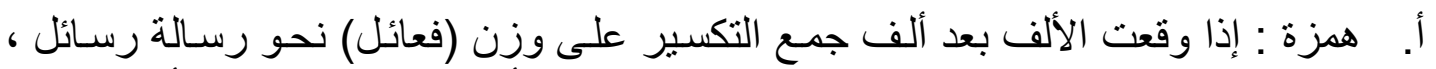

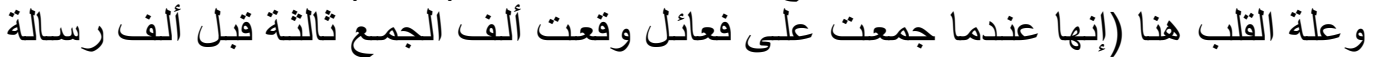

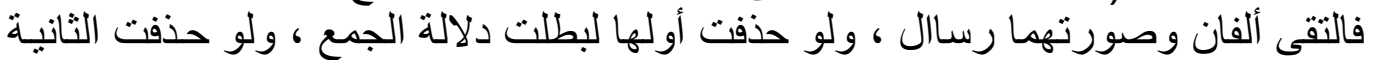

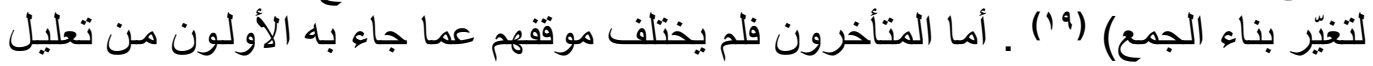
لتلاك الحالة .

ب. واو : تقلب الألف واواً إذا انضم مـا قبلها نحو : حوكم والأصل حساكم (عند بنـاء الفعل

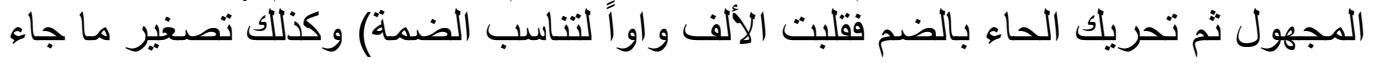

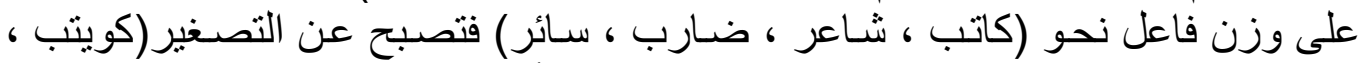

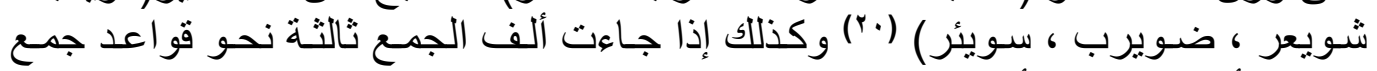

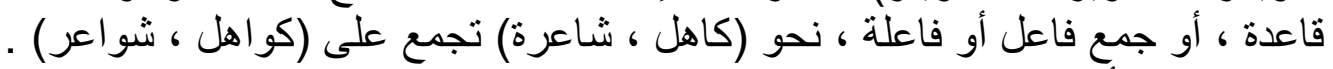

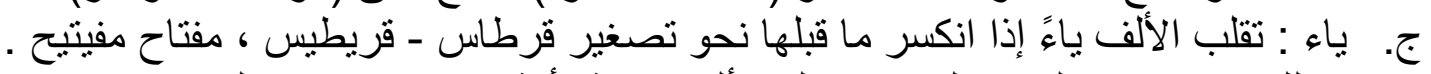

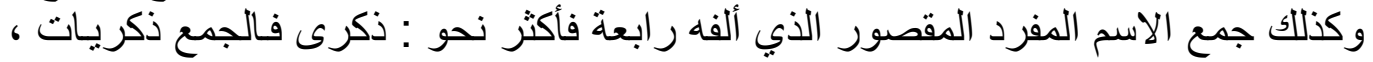

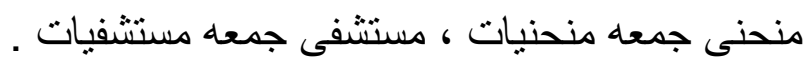
وقد علل ابن جني قلب الألف واواً أو ياءً قائلاً (فهذا ونحوه مما لا بد منه قيل إنه ليس في القوة ولا احتمال الطبيعة وقوع الألف المدة الساكنة بعد الكسرة الضمة )

$$
\text { ب. قلب الواو و الياء همزة : }
$$


القاعدة الصرفية تقول : (إذا تطرفت الواو أو الياء بعد ألف زائدة اي إذا وقعت آخر الكلمـة

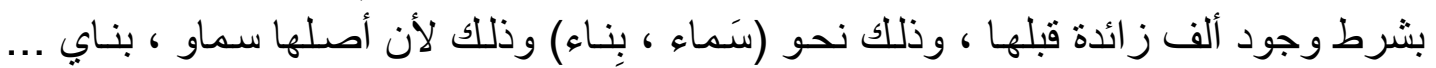

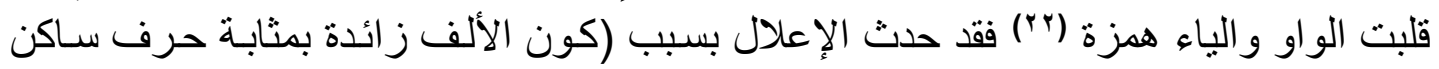

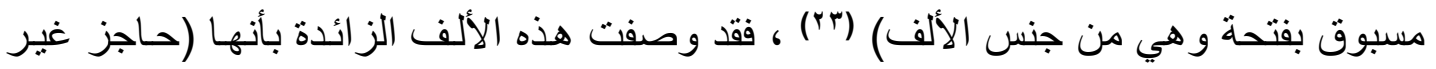

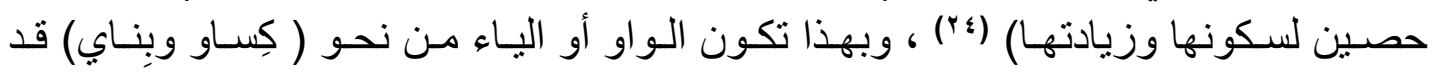

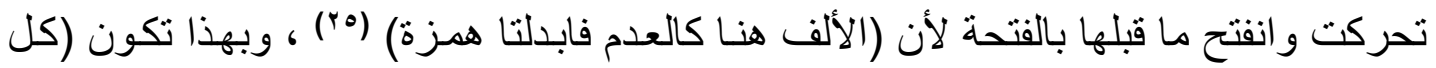

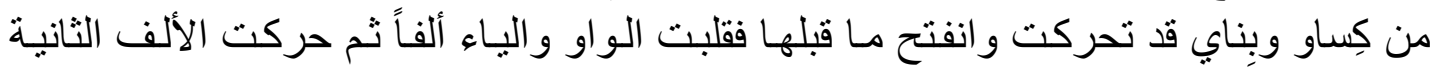
فقلبت همزة) (Tب (Y) ، فالهمزة في الحقيقة هي بدل عن الألف. أما ابن جني فانه يعرض لهذه المسألة بقوله ((إنما أجروا الألف في كساء وراء مجرى الفتحة

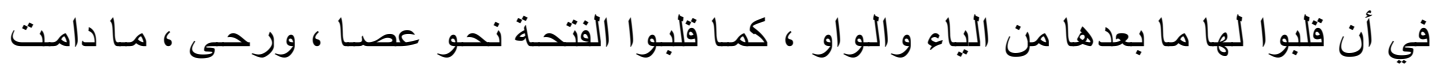

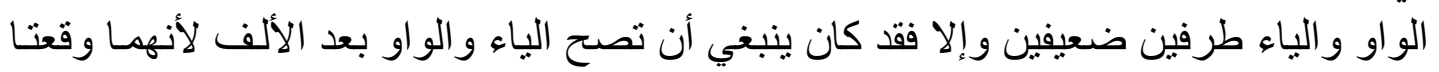

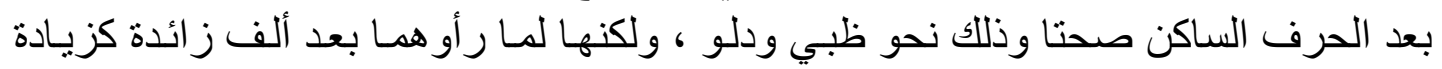

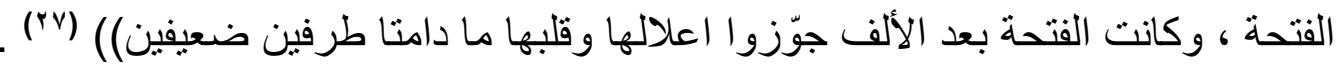

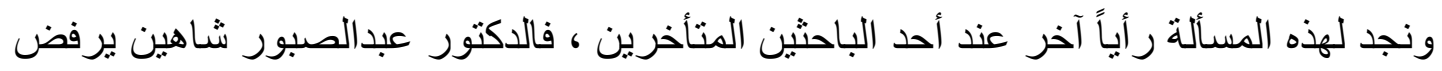

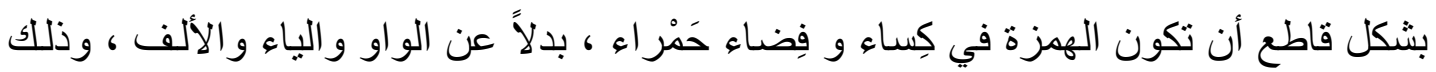

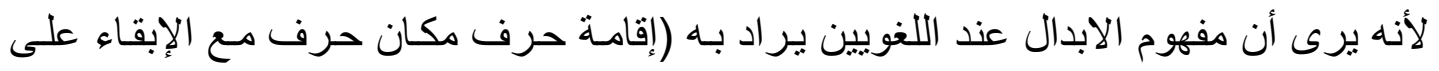

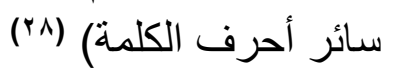

فهو هنا ينتقد المتقدمين لأنهم لم يتناولوا العلاقة بين الهمزة و المصوتات الطوال من حيث هي

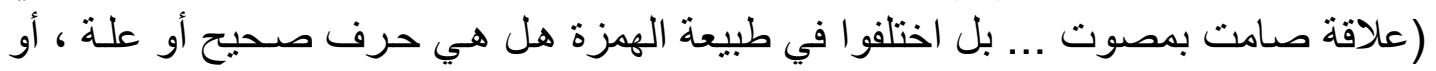

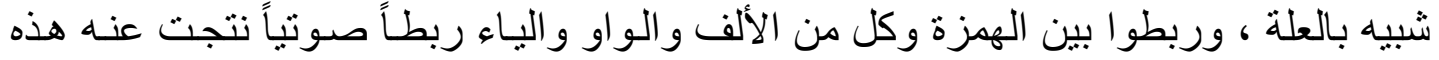

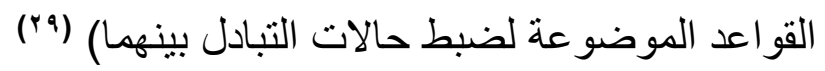

و عالج الدكتور عبد الصبور شـاهين الكلمات : كِساء ، بِناء ، حَمْر اء في حالة واحدة هي حالة

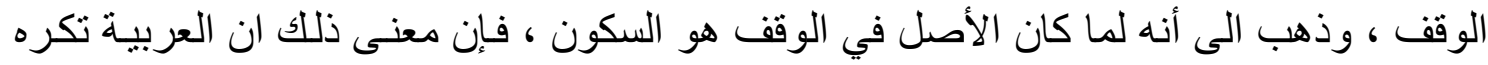

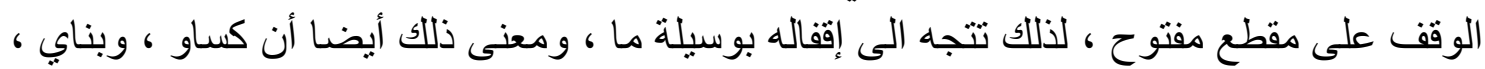
و أمثالهما ينتهي المقطع الأخير من كل منهما بحركة ، هي احد عنصري الحركة المزدوجة ، التي

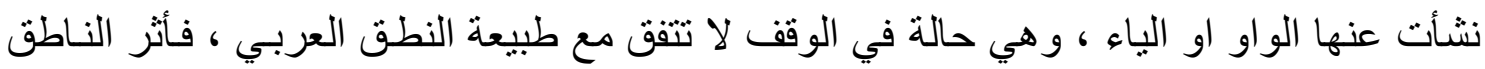

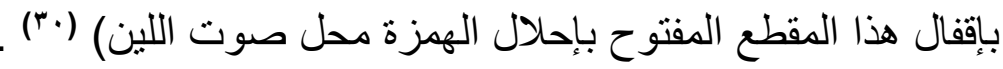

في حين يرى الدكتور حسام النعيمي ( إن العلاقة بين الهمزة و الواو و الياء موجودة في ذهن الهن

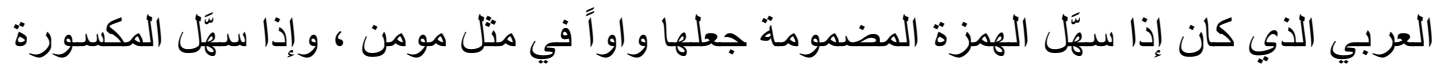




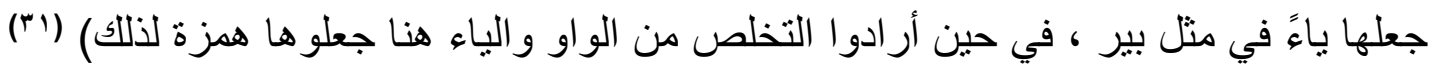
ـ ومما تقدم يتضح أن حرف الهمزة هو أقرب الحروف الى الألف فضلا عن عن العلاقة السياقية

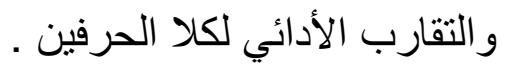
الهزةة إذا وقعت عيناً في اسم الفاعل :

( إن الإعـلال في الأفعـال اقوى منـه في الاسـماء لأن الأفعـال موضـوعة للتنقل في الأزمنة

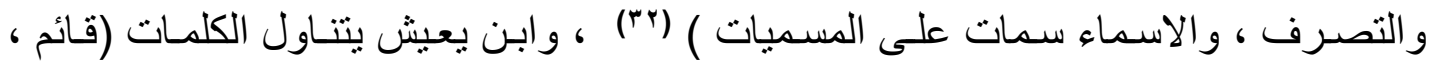

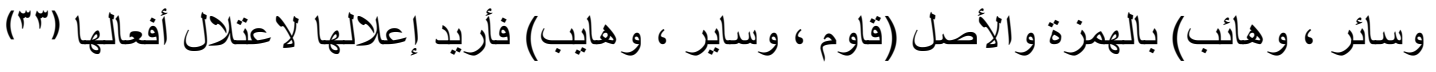

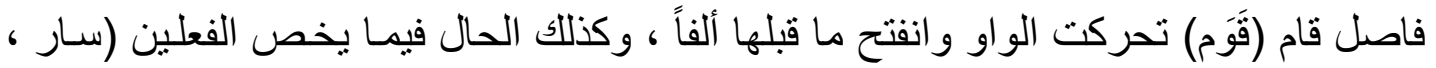

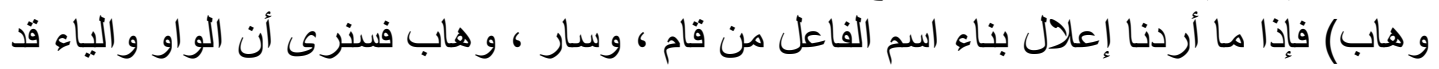

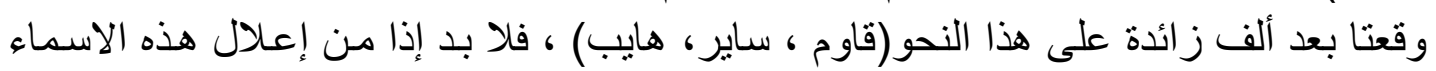

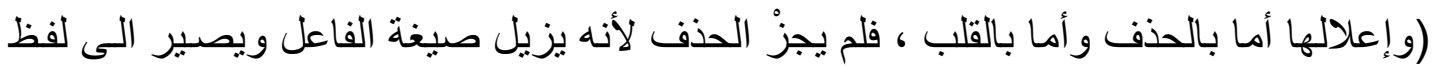

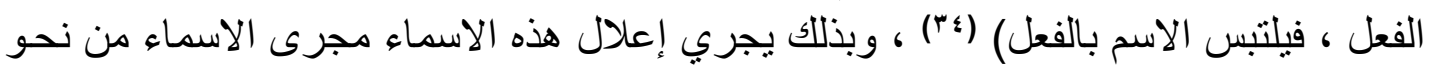

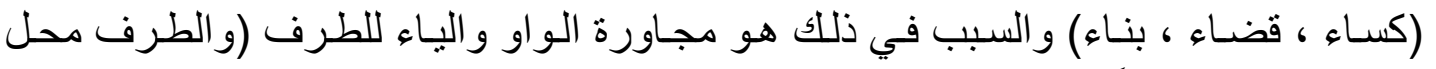

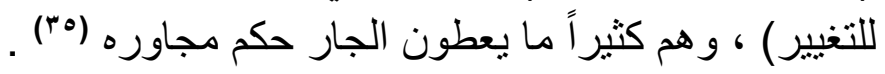

ونرى ابن جني يعرض لهذه المسألة بقوله (إنما وجب همز عين اسم الفاعل ، لأن العين لما

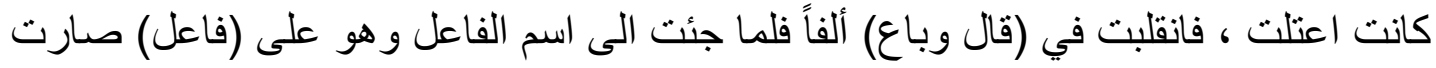

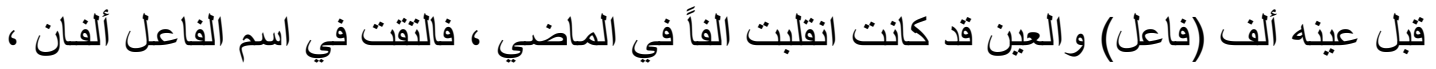

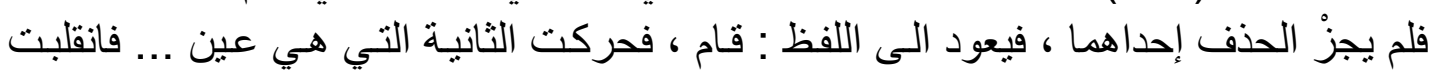

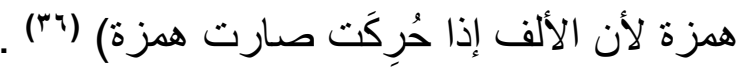

ويرى باحث آخر في علاج هذه المسألة أن سبب الإعلال هو النطق بمجموعة من الكر اهـات

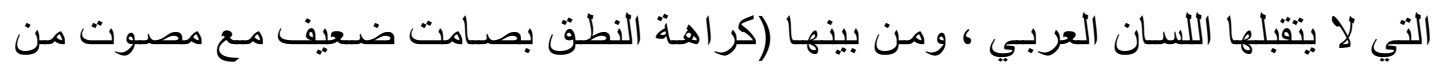

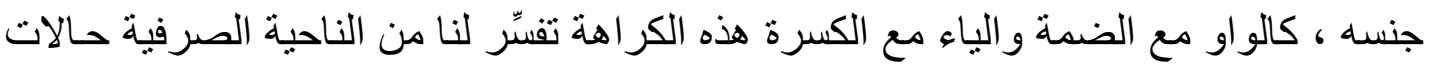
كثيرة من المخالفة عند إبدال الواو و الياء همزة ، فاسم الفاعل من الفعل الأجوف بالو الواو أو أو الياء

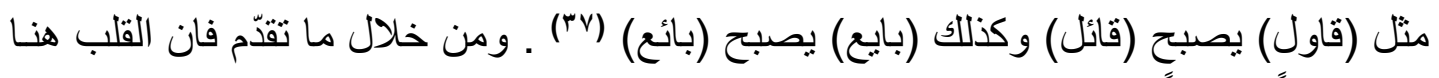

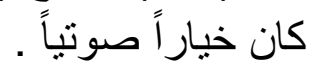
ع. قلب الواو و الياء ألفاً : 
يتناول هذه المسألة ابن جني فيقول (هذا الموضوع كثير الايهام لأكثر من يسمعه ، لا حقيقة

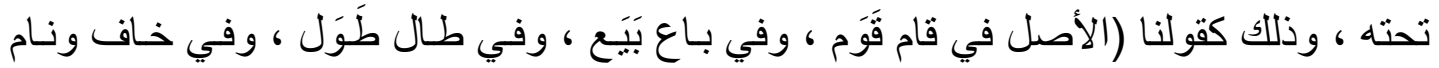

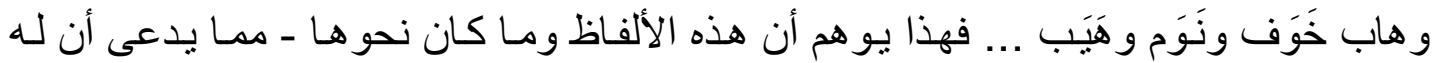

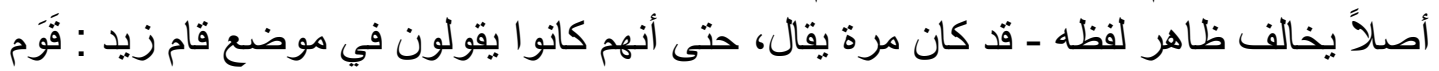

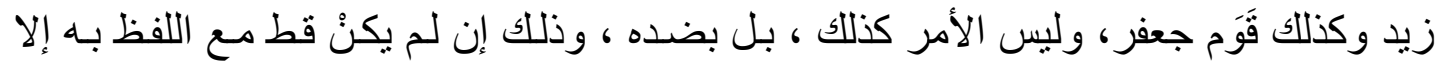

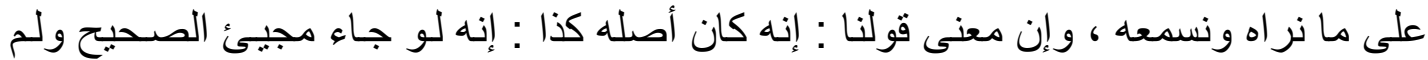

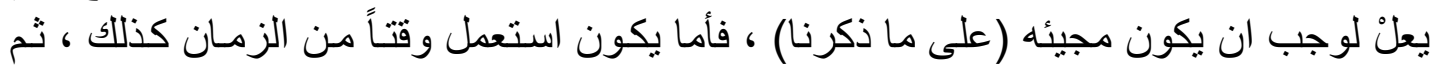

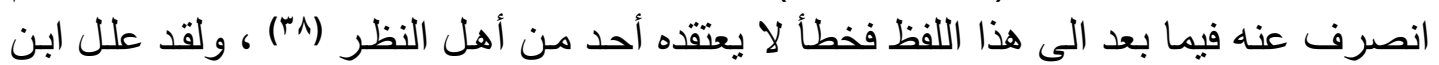

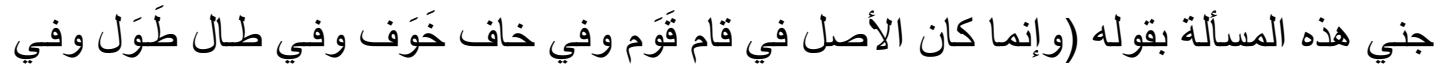

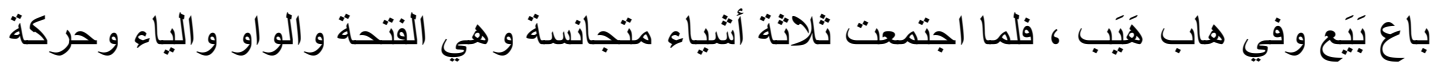

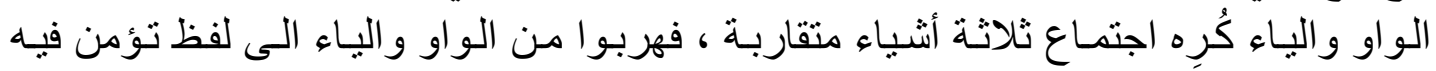

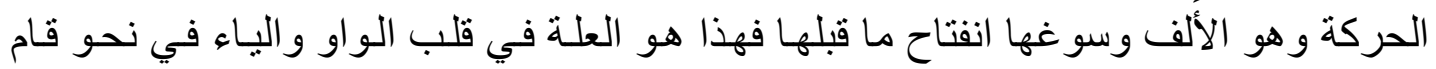

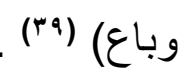

إن هذا التعليل قد يُعدُّ مقبو لاً من الناحية الصوتية (.؛) ، لكنه من الناحية الوظيفية يبدو أنه غير

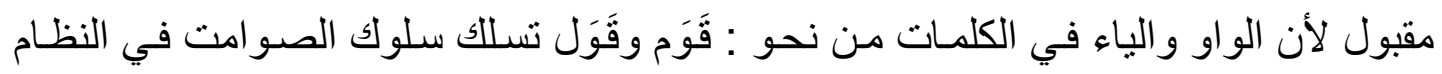

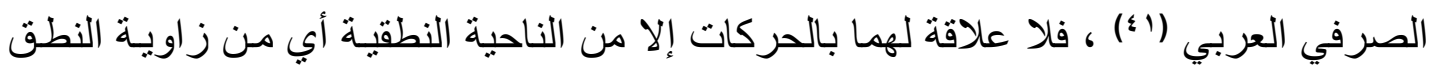

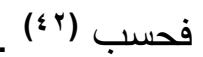

إما ابن عصفور الإشبيلي فانه يعلل لهذه المسألة بقوله (و أما فَعَل فتقلب الواو و الياء فيها الفـاً

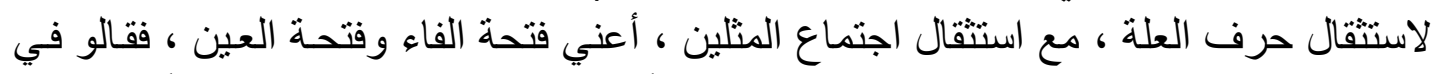

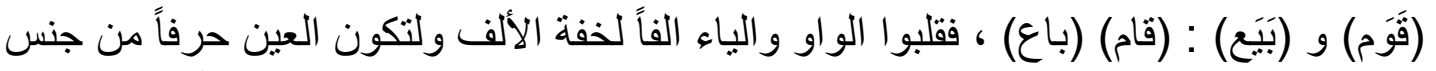

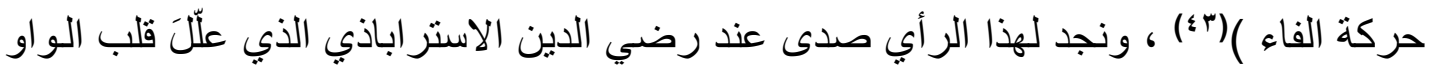

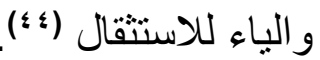

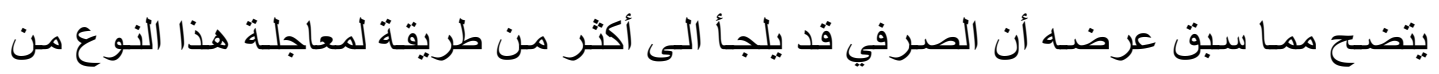

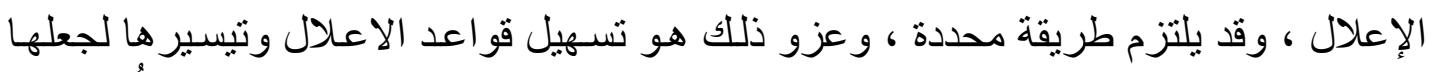

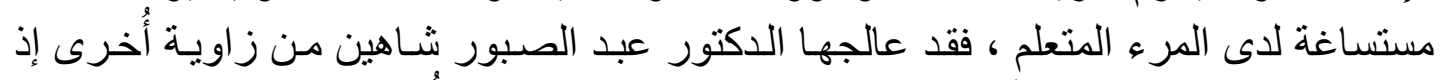

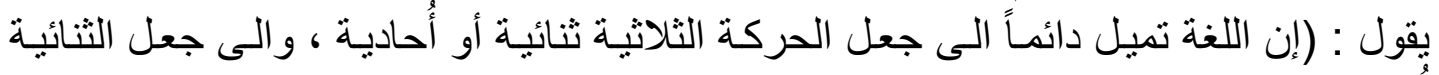

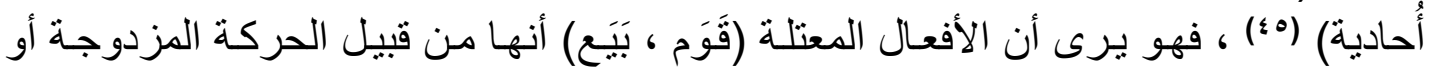

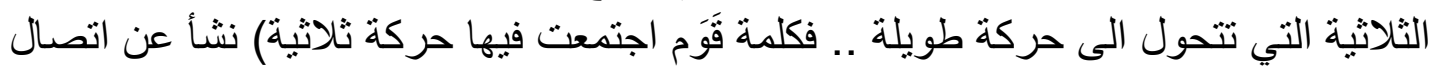

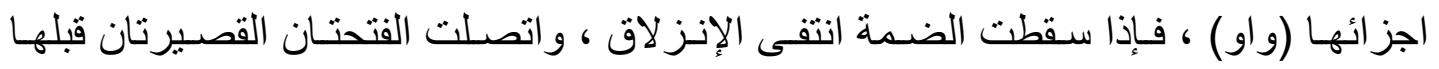


وبعدها ... فكل ما حدث هو إسقاط عنصـر في واقع الأمـر ، هروبـاً من ثنلاثيـة الحركة الى لى

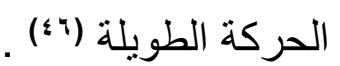

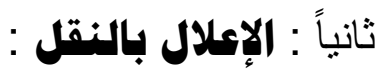

هو نقل حركة الحرف المعتل الى الحرف الصـحيح السـاكن قبلهـه ، ويكون في حرفي

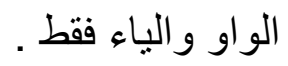

أو هو تسكين الحرف المعتل في الكلمة إذا كان متحركاً ، ومـا قبله صحيحاً سـاكناً بنقل

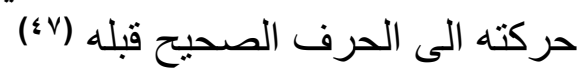

إعلال الفعل الأجوف : وهو الإعلال الناثـئ عن نقل حركة احد الأصسوات المعتلة (الواو ،

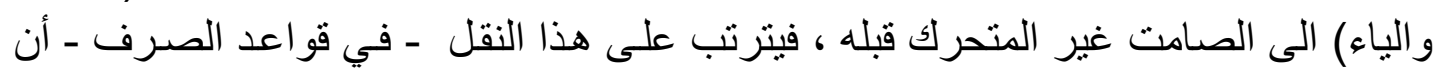

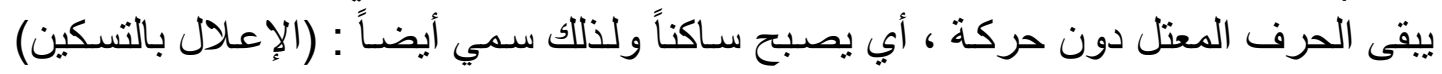

في حين تناول سييويه ما جاء بصيغة الماضي كـ (استقام ) و المضار ع ك (يخاف) ذاكراً علـة ألها

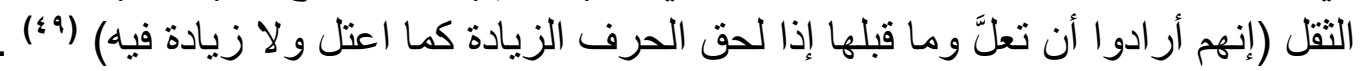

اما ابن يعيش فعـالج هذه المسألة بقوله : ( إن الأفعال من نحو يقوم ، يبيع ، يخاف، يهاب

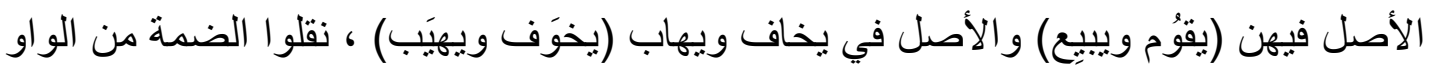

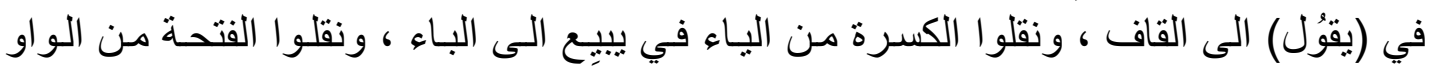

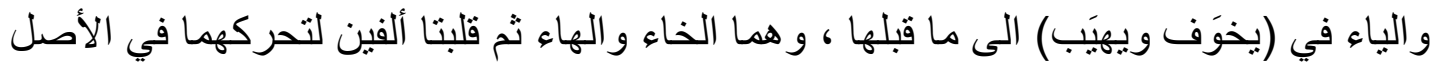
، و انفتاح ما قبلهما الآن ، ففي هذين الفعلين نقل وقلب وفي (يقوُل ويبيع) نقل فقط (.0) .

وسبب الإعلال في رأيه (إنما وجد إعلال المضار ع في هذه الأفعال مـع سكون مـا قبل الواو

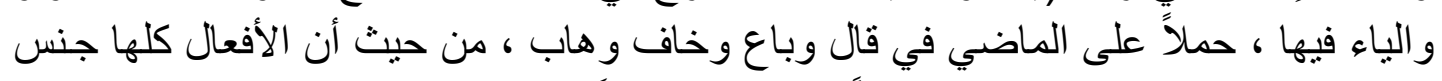

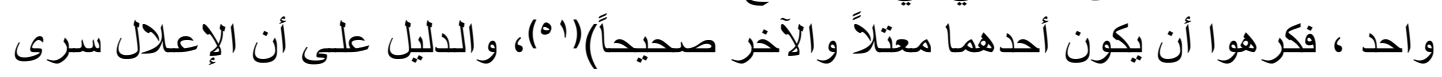

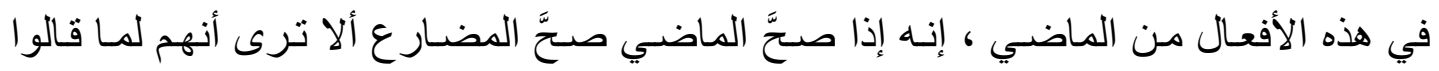

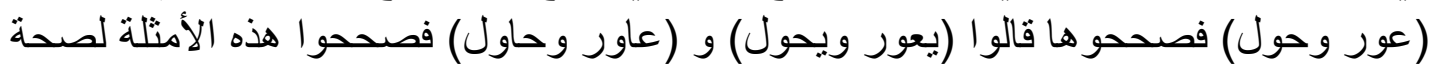

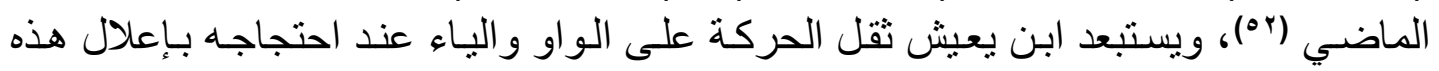

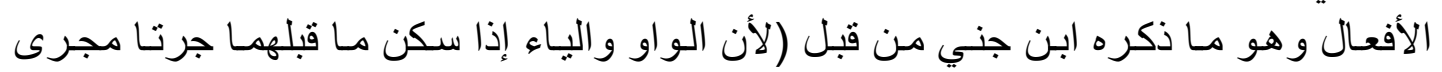

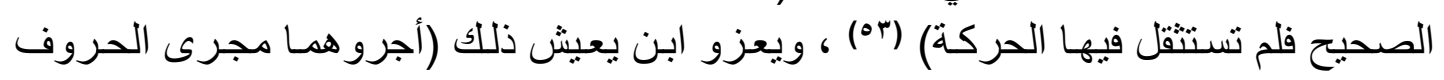

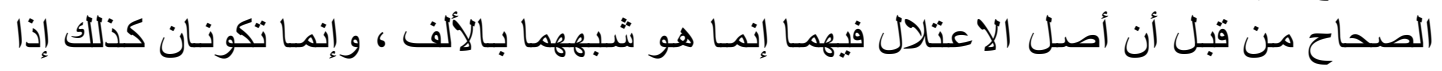

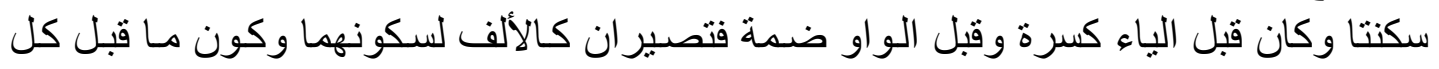




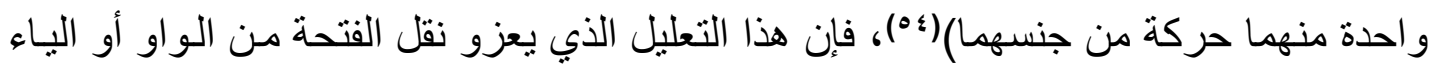

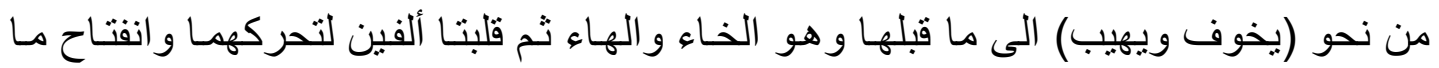

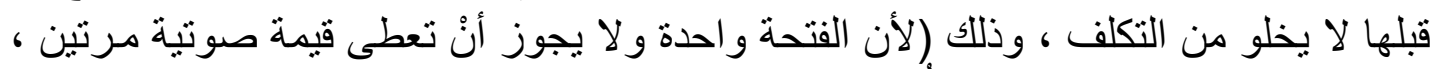

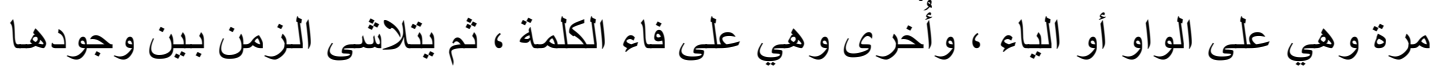

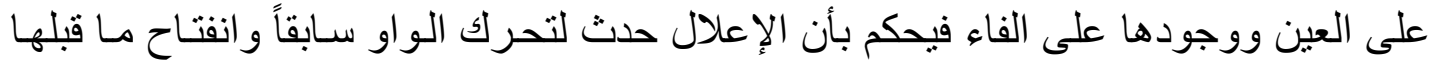

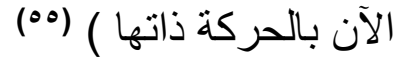

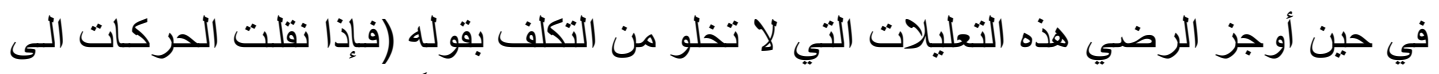

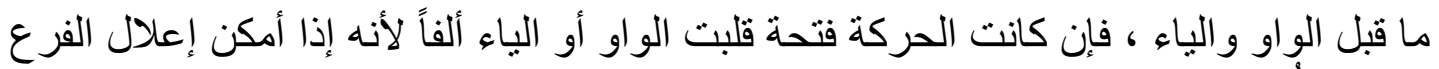

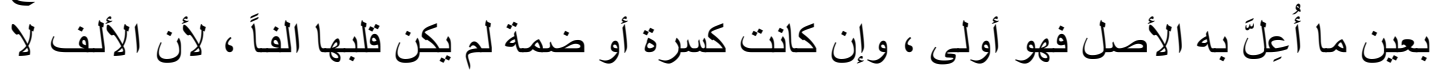

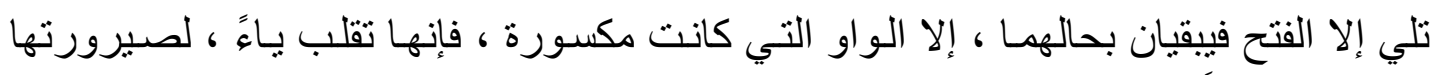

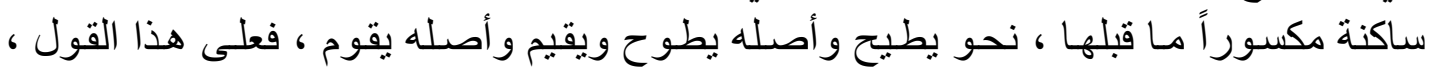

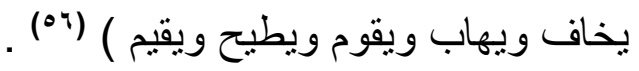

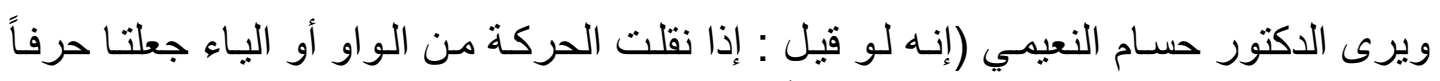

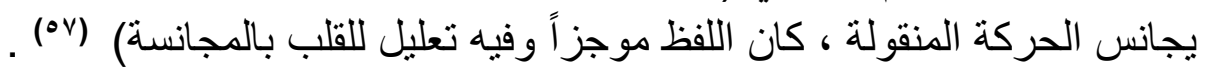

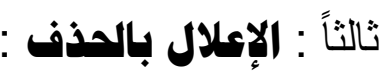

وهو تغيير بطر أ على بنية الكلمة بحذف بعض حروفها أو إسقاطها ، فينقص من بنائها

و الحذف قسمان : حذف سماعي وحذف قياسي (09).

و الحذف القياسي يخضـع لقاعدة صـرفية كالاستثقال او لالتقاء السـاكنين .و أكثر الأصـوات

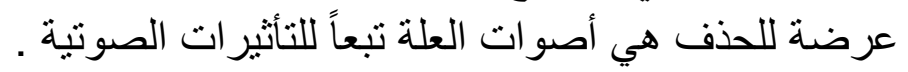

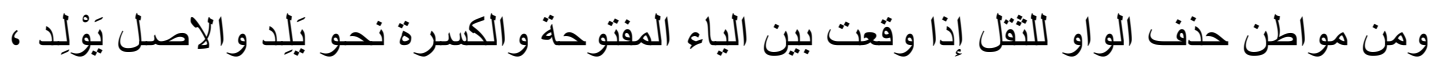

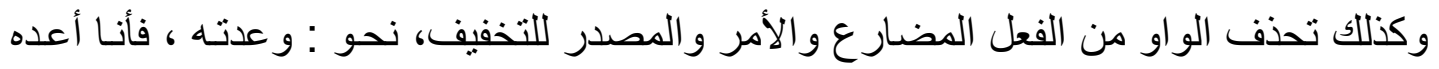

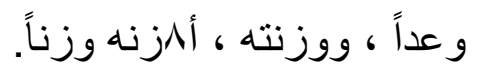

ومنه كذللك حذف الياء للتخفيف كما في سيّد ميّت ، إذ لم تحذف العين ، و علة الحذف كما ذكر

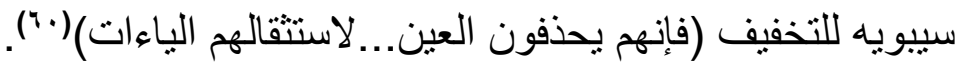

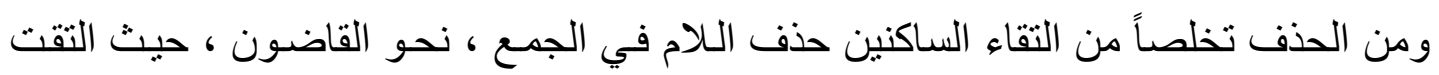

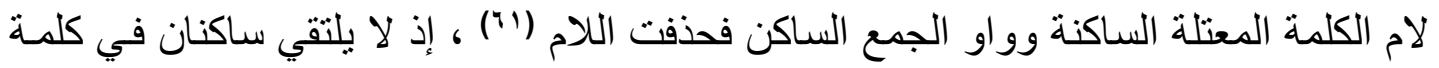


واحدة ، لأن التقاء الساكنين لا يجوز ، بل هو غير ممكن (وذلك من قبل أن الحرف السـاكن

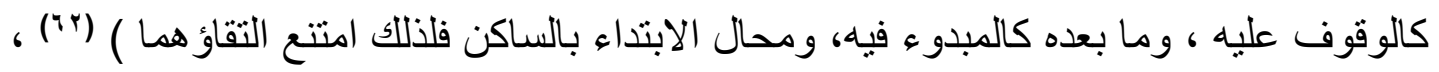

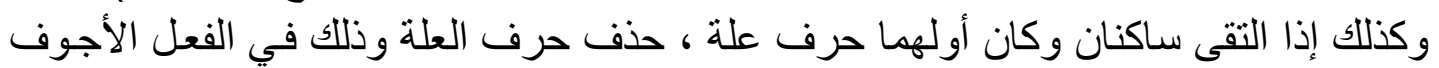
بالواو أو الباء.

ومنه كذلك حذف عين الفعل الماضي الأجوف عند إسناده الى ضمير الرفع المتحرك نحو : قلت ، نلت .

وكذللك حذف عين المضار ع الأجوف المجزوم نحو: لم يقُلْ ، لم بيِغْ . ومن مو اطن الحذف أيضاً حذف الهزة للتقل من الفعل المضارع واسم الفاعل واسم المفعول

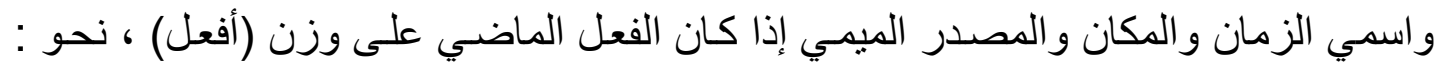

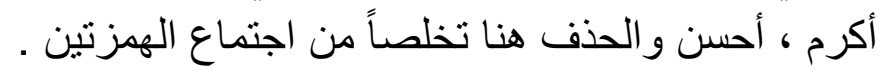

و هنالك نماذج أخرى من الحذف وهي أما للتخلص من التقاء الساكنين أو للتخفيف(ب"). ولعلماء العربية المتقدمين في هذه الظـاهرة كلام طويل ، و علل لا مجـال لحصر ها أو ذكر هـا هنا (؛)

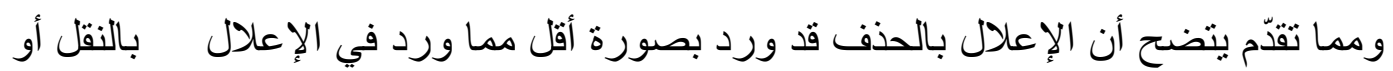

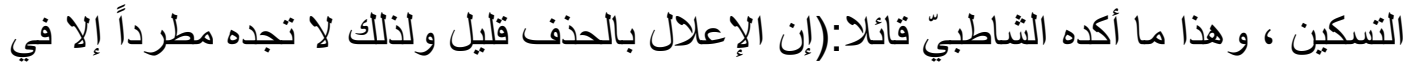

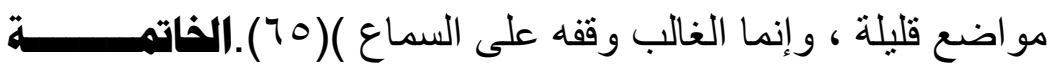

بعد هذه المسيرة التي صحبنا فيها طائفة من الكتب الصرفية القديمـة والحديثة يتضـح مدـا

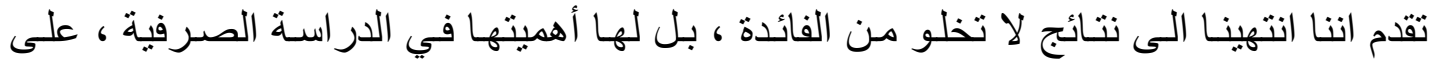

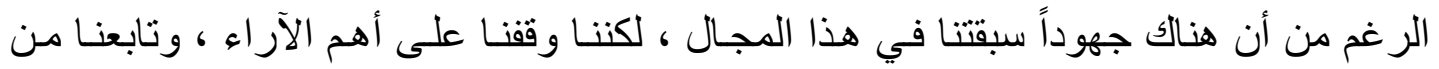

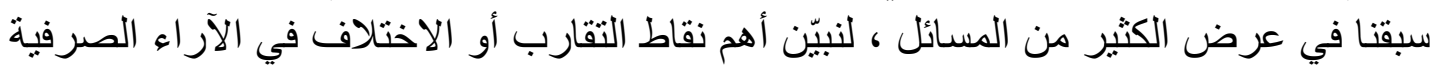

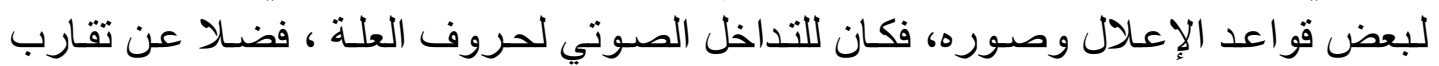
طبيعتها الأدائية وكثرة الاستعمال أثر واضح في تعليل بعض مظاهر الإعلال ، فبدا جليا تباين

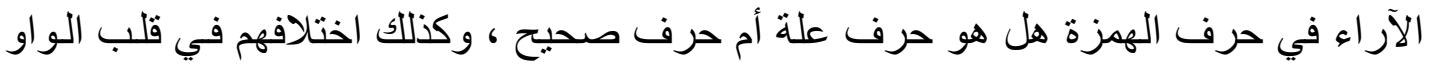

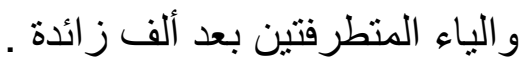

لقد حاولنا جهد الإمكان أن نوجز في عرض الأمثلة ، لأنتا حاولنا عرض الآر اء، وثنتنا الرأي

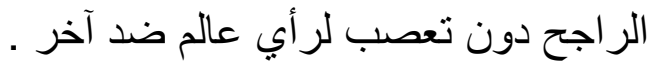




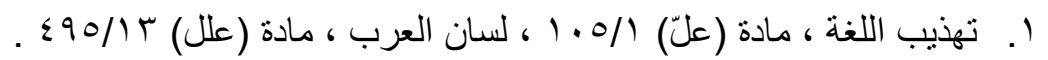

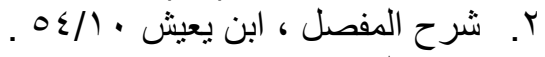

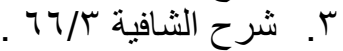

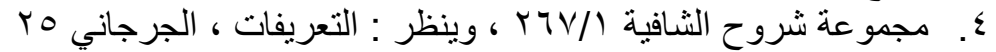

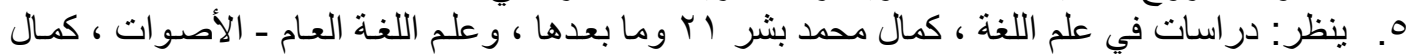

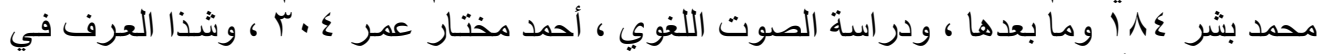

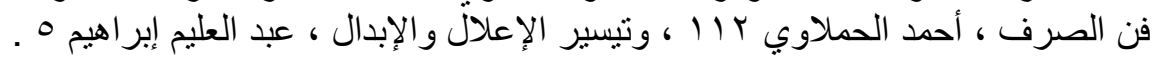

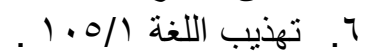

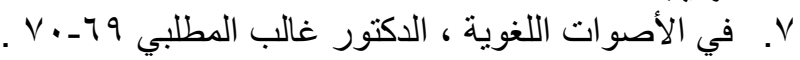

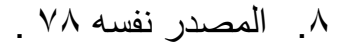

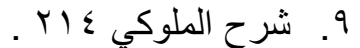

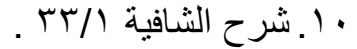

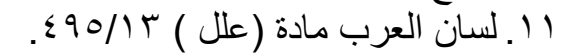

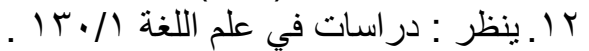

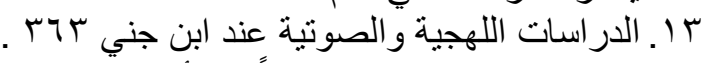

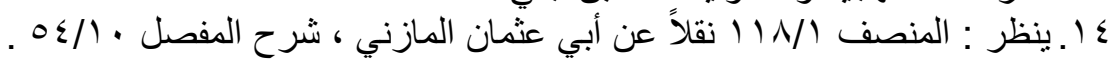

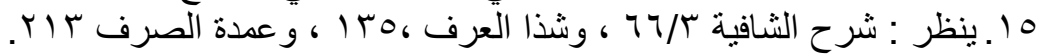

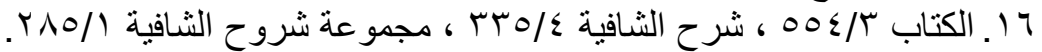

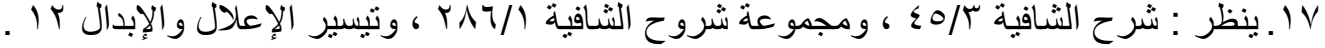

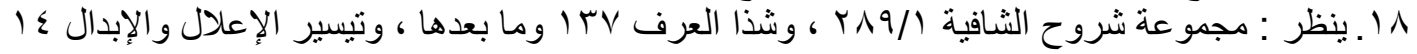

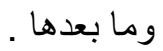

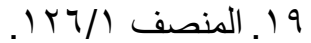

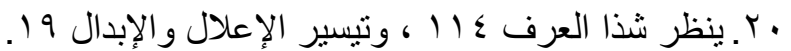

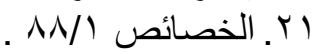

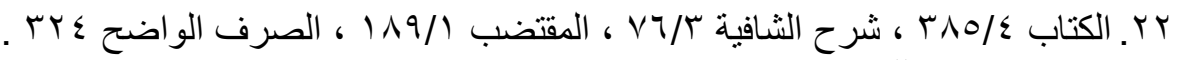

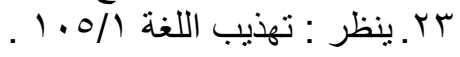

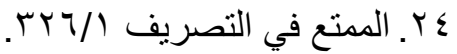

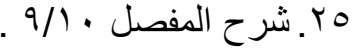

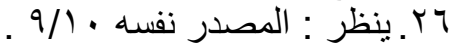
. $9 V / /$. TV

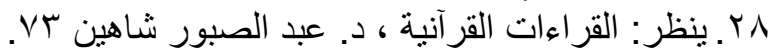

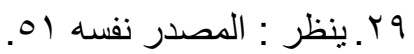

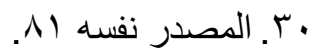
آبـ ينظر : الدراسات اللهجية و الصوتية عند ابن جني بآب.

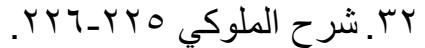

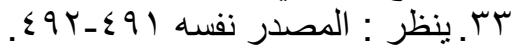

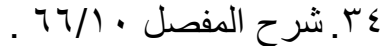

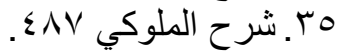

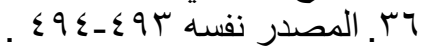

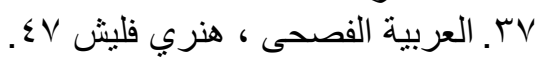




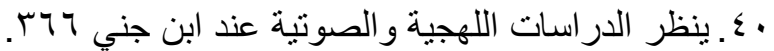

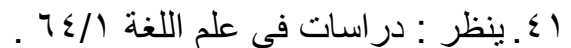

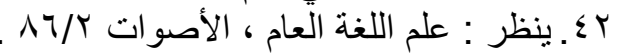

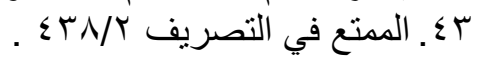

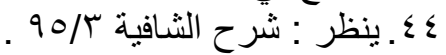

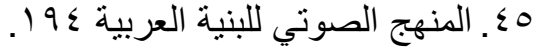

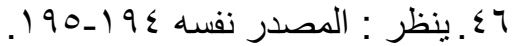

SV

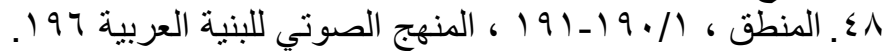

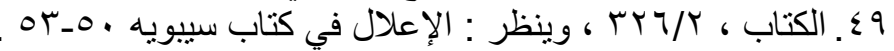
• 0.

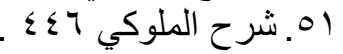
أبr

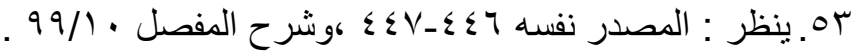

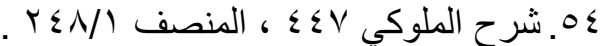

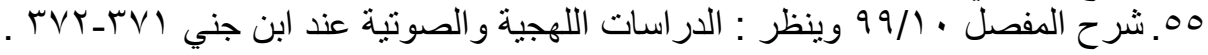

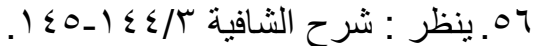

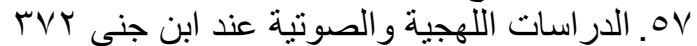

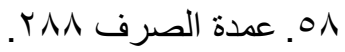

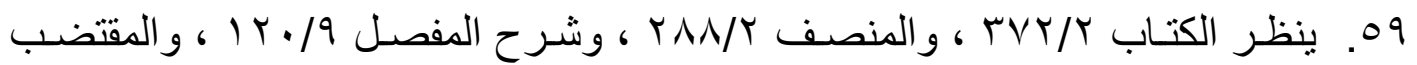
$.1 \mathrm{ro/1}$

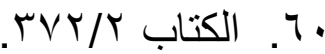
( T r T. شر ح المفصل

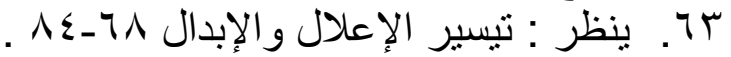

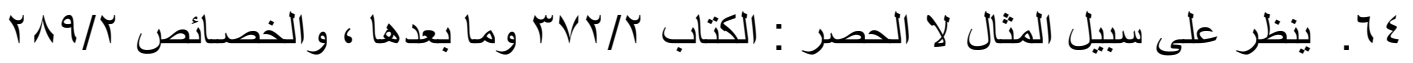

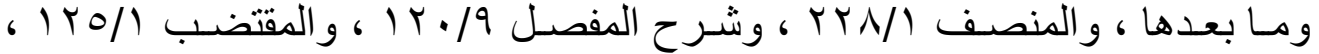

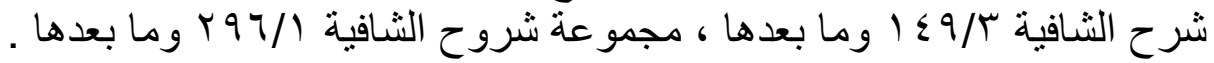

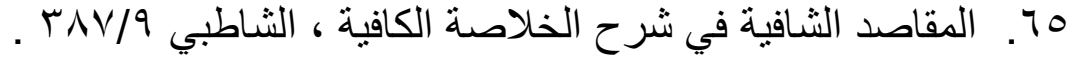

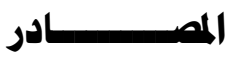

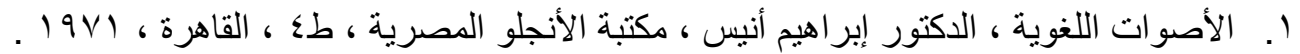

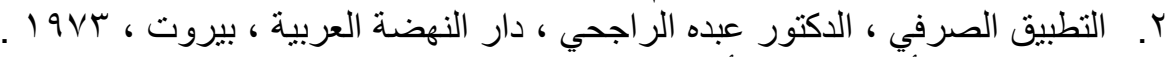

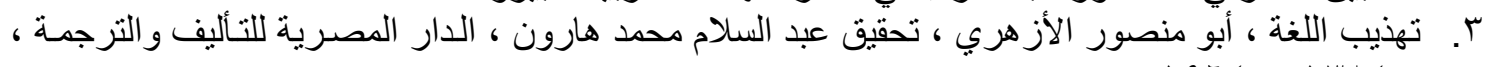

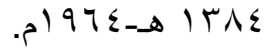

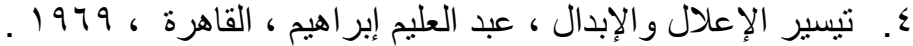

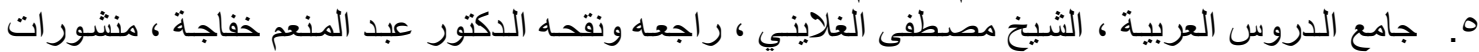

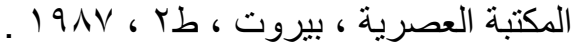




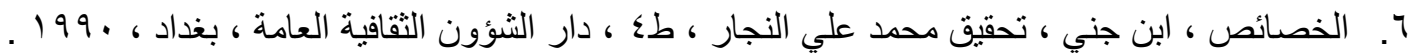

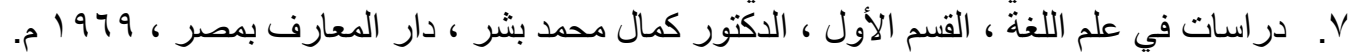

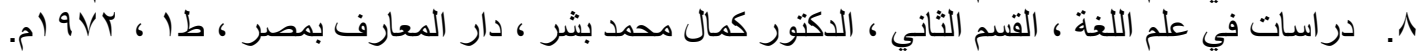

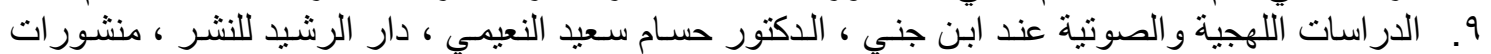

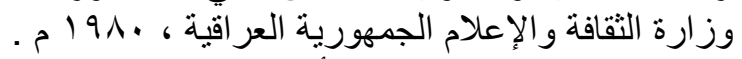

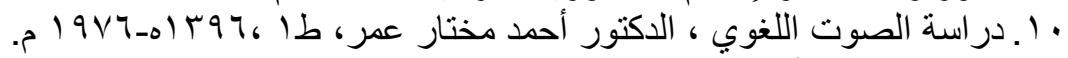

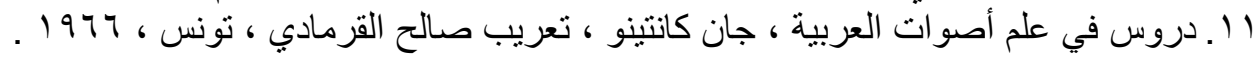

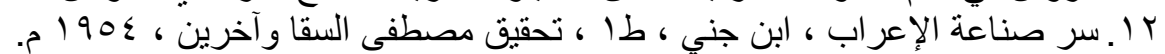

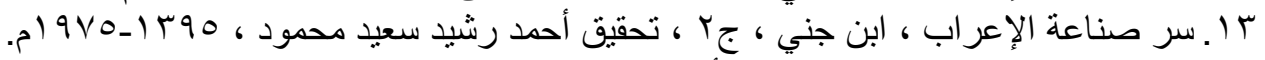

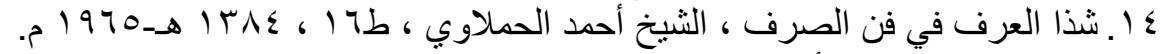

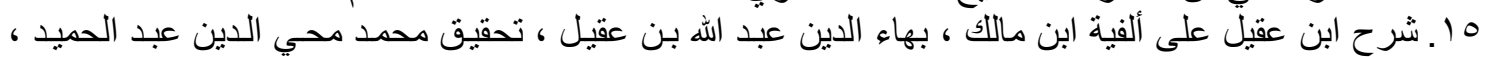

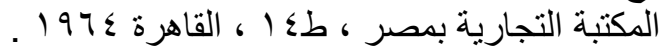

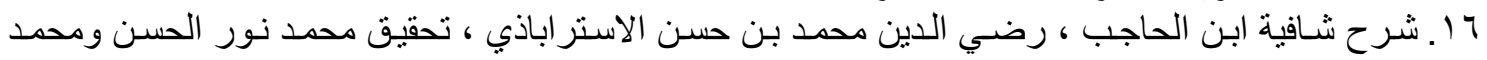

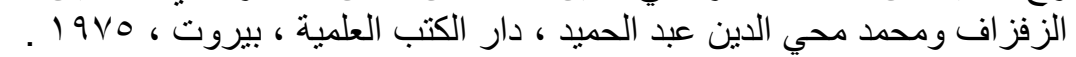

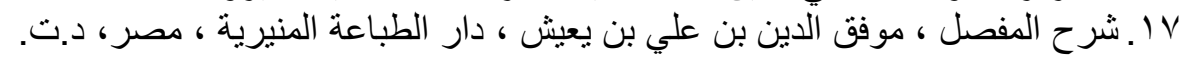

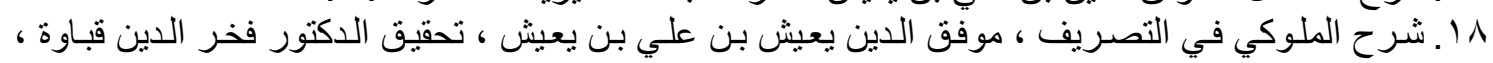

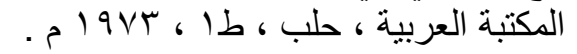

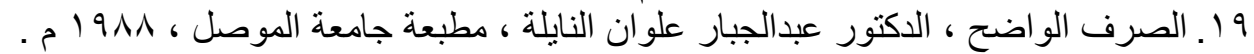

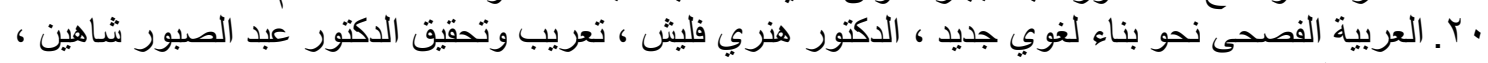

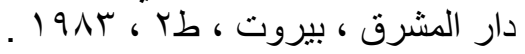

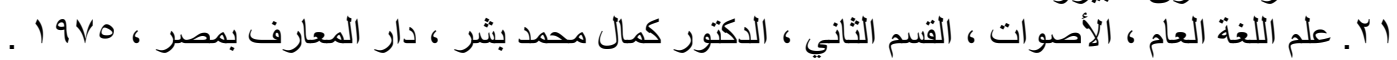

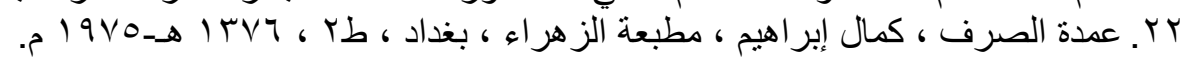

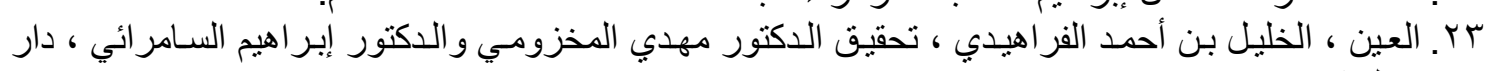

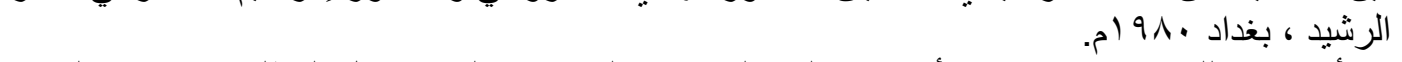
ع ז. في الأصـوات اللغويـة ، دراسـة في أصسوات المـد العربيـة ، الدكتور غالب فاضل المطلبي ، وزارة الثقافة

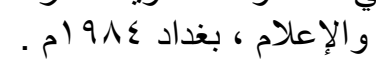

هץ. القراءات القرآنية في ضواء غوه علم اللغة الحديث ، الدكتور عبد الصبور شـاهين ، دار الكاتب العربي للطباعة

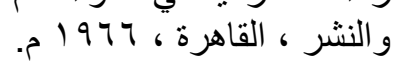

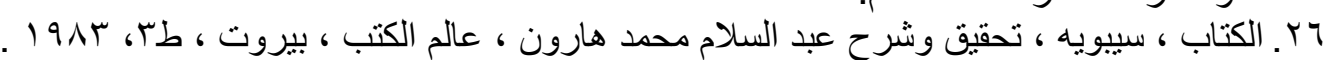

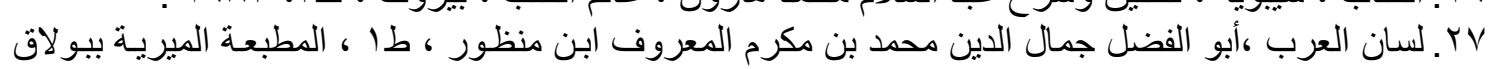

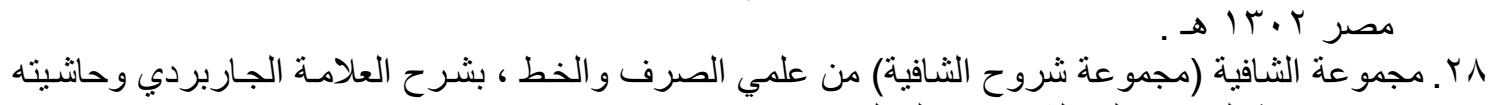

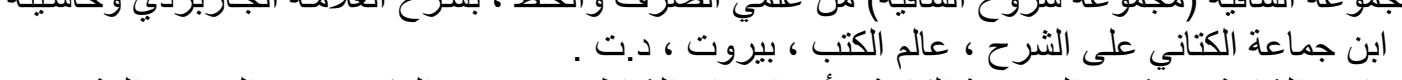

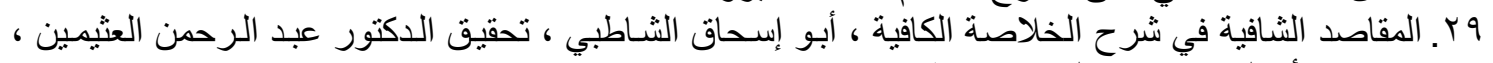

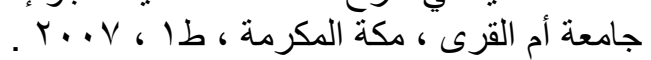

• ؟. المقتضب ، أبو العباس محمد بن يزيد المبرد ، تحقيق محمد عبدالخالق عظيمة ، عالم الكتب ، بيروت ، د.ت

اسـ. الممتع في التصريف ، علي بن مؤمن بن عصفور الاشبيلي ، تحقيق الدكتور فخر الدين قباوة ، منشورات

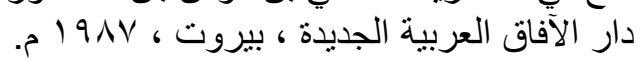

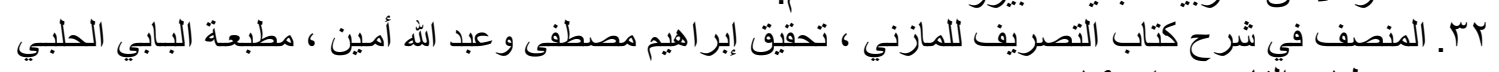

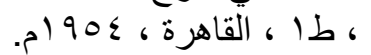

سب. المنهج الصـوتي للبنيـة العربيـة رؤيسة جديدة في الصـرف العربـي ، الدكتور عبد الصبور شـاهين ، مؤسسـة

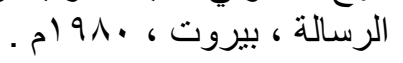


Abstract

Vowel change (Ilal) is a common term in the morphology of the Arabic language, and is related to phonology and dialects. It is important in Arabic language studies as a phono-logical phenomenon that is governed by precise rules the purpose of which is to create eu-phony. The paper deals with the types and the classification of the vowel changes and investigates the controversy between the traditional and the modren scholars, with an attemp to see the differeneces and similarities between their morphological view point . 